\title{
Peran Grit pada Subjective Well-Being Siswa Madrasah Aliyah di Pesantren
}

\section{The Role of Grit on Subjective Well-Being of High School Student in Boarding School}

\author{
Nafi'atul Badi'ah \\ Fakultas Psikologi dan Kesehatan, Universitas Islam Negeri Sunan Ampel \\ naafiah1206@gmail.com
}

\begin{abstract}
Abstrak
Tujuan penelitian ini yaitu untuk mengetahui hubungan antara grit dengan subjective well-being pada siswa MA di pesantren. Metode yang digunakan pada penelitian ini yaitu kuantitatif dengan melihat korelasi atau hubungan antara dua variabel, yaitu grit dan subjective well-being. Penelitian ini menggunakan teknik pengumpulan data dari skala grit scale dan $B B C S W B$. Populasi yang digunakan pada penelitian ini adalah seluruh siswa MA yang berjumlah 372 siswa. Sedangkan sampelnya berasal dari seluruh kelas X dengan jumlah 113. Analisis data data yang digunakan yaitu product moment dengan perolehan nilai koefisien korelasi sebesar 0,360 dan signifikansinya $0,000<0,05$. Dari hasil tersebut mengatakan bahwa terdapat hubungan positif antara grit dengan subjective well-being pada siswa MA di pesantren. Temuan lain pada penelitian ini yaitu bahwa siswa MA di pesantren memiliki tingkat subjective well-being yang tinggi dan tingkat grit yang rendah.
\end{abstract}

Kata kunci: subjective well-being, grit, siswa MA

\begin{abstract}
The purpose of this research is to find out the relationship between grit and subjective well-being in high school student in boarding school. The method used in the research is quantitative by looking correlation or relationship between the two variables, namely grit and subjective well-being. The research uses data collection techniques from the grit scale and BBC SWB scales. The population used in this research is the total number of 372 high school student. The sample came from the whole $X$ class of 113 . The data analysis used is product moment by providing a coefficient correlation value of 0.360 and its significance is $0,000<0.05$. From the results it says that there is a positive relationship between grit and subjective well-being in high school student in boarding school. Another discovery in the research is that high school student in boarding school has a high subjective well-being level and a low grit level.
\end{abstract}

Keywords: subjective well-being, grit, high school student. 


\section{Pendahuluan}

Sudah sejak lama, pendidikan merupakan salah satu sarana demi peningkatan kualitas hidup masyarakat Indonesia. Agar terwujud, maka pemerintah Indonesia menyelenggarakan satuan pendidikan yang bersifat formal dengan jenjang tertentu yang disebut sekolah. Menurut UndangUndang Nomor 20 Tahun 2003, masyarakat di Indonesia diwajibkan menempuh pendidikan sekurang-kurangnya 9 tahun, yaitu hingga tingkat Sekolah Menengah Pertama (SMP) atau yang sederajat.

Meski begitu, kemajuan teknologi menjadikan masyarakat lebih sadar akan pentingnya pendidikan bagi mereka. Terlihat dari banyaknya masyarakat yang melanjutkan pendidikan di jenjang Sekolah Menengah Atas (SMA) atau yang sederajat hingga di tingkat perguruan tinggi. Selama menempuh pendidikan, pastinya sekolah banyak memberikan pengaruh yang signifikan bagi kehidupan para siswa. Sebab sebagian besar watunya tak jarang dihabiskan di sekolah. Berbagai pengaruh didapatkan, bisa dari teman sebaya, guru, maupun pekerja dan orang lain yang berada di tempat mereka menempuh pendidikan tersebut.

Begitu juga sekolah yang menggunakan sistem pesantren, di mana para siswa wajib tinggal di asrama yang telah ditetapkan selama dua puluh empat jam. Mereka berinteraksi dengan teman sebaya, guru, maupun orang lain yang ada di pesantren setiap hari juga selama dua puluh empat jam. Dari interaksi tersebut, pastinya berbagai masalah akan muncul. Di pesantren sendiri, permasalahan tidak hanya dari orang lain, namun keadaan lingkungan pesantren seperti kebersihan, peraturan, pelajaran, juga ikut mempengaruhi. Meski begitu, nyatanya mereka bisa bertahan hingga lanjut tingkat MA dan berusaha menyelesaikan masalah tersebut. Hal ini terlihat dari observasi yang dilakukan di salah satu pesantren di Tulungagung bernama Pondok Pesantren Darul Hikmah. Para santri berusaha menerima dan melakukan kegiatan positif. Beberapa ekstrakurikuler yang ada di pesantren mereka ikuti, baik yang bersifat wajib mau pun tidak. Merkea juga berusaha mengikuti anjuran untuk tetap di pesantren selama enam tahun hingga lulus MA. (observasi, 2020)

Berbagai masalah yang bisa bersumber dari mana saja akan mempengaruhi subjective wellbeing para siswa. Menurut Seligman (2011) subjective well-being merupakan kombinasi antara memiliki perasaan baik tentang dirinya sendiri, makna hidup, serta pencapaian hubungan dengan orang lain. Pendapat lain dari Diener dalam Akbang (2017) mengatakan bahwa subjective wellbeing merupakan kemampuan individu untuk melakukan evaluasi tentang kehidupan yang telah dan sedang dilalui, evaluasi ini berasal kognitif dan afektif. Selain itu, menurut Diener (2003) subjective well-being juga didefinisikan sebagai pengalaman batiniah seseorang dan hanya dirinya sendiri yang bisa mengukur. Menurut Pontin, Schwannauer, dan Kinderman dalam Faridl (2018) subjective well-being merupakan penilaian individu tentang dirinya mengenai gambaran kesejahteraan yang mencangkup lingkungan di sekitar individu, respon perilaku yang dilakukan dan juga konsekuensi subjektif dari saling keterkaitan antara proses tersebut. Individu dengan subjective well-being tinggi, ia akan merasa nyaman ketika berada di lingkungannya meski banyak permasalahan yang dihadapi.

Terdapat dua faktor yang dapat mempengaruhi terbentuknya subjective well-being, yaitu faktor internal yang berasal dari dalam individu dan faktor eksternal yang bersalah dari luar individu. Faktor internal seperti mindset (Zeng, 2019) dan grit (Jin, 2017). Sedangkan faktor eksternal seperti dukungan orang terdekat (Wijayanti, 2015) serta hubungan dengan orang tua (Lampropoulou, 2018). Dua faktor tersebut bisa mempengaruhi terbentuknya subjective well-being: Namun, Menurut Hossaini (2019) faktor internal lebih berpengaruh dalam mewujudkan subjective well-being.

Menurut Duckworth (2007) grit merupakan kecenderungan untuk mempertahankan ketekunan dan semangat atau keinginan yang besar dalam mengejar tujuan jangka panjang. Pada penjelasan lainnya, Duckworth mengatakan jika grit mencakup kemampuan pengendalian diri dan kesadaran untuk mempertahankan dalam mencapai tujuan yang mungkin membutuhkan waktu berbulan-bulan atau bahkan lebih lama untuk mencapai tujuan yang diharapkan. Orang yang memiliki grit cenderung fokus pada tujuan tertentu, ulet, dan mampu mengatasi hambatan untuk mencapai hasil yang ditentukan (Malin, Liauw, \& Damon dalam Weisskirch, 2019).

Penelitian yang menunjukkan bahwa grit dapat mempengaruhi subjective well-being pada seseorang yaitu penelitian yang berjudul Grit and Different Aspects of Well-Being: Direct and 
Indirect Relationships via Sense of Coherence and Authenticity dilakukan oleh Vainio (2015) pada mahasiswa dan non mahasiswa. Pada penelitian ini dikatakan bahwa terdapat hubungan positif antara grit dan subjective well-being. Penjelasannya melalui uji korelasi yang mengungkap nilai signifikansi $\mathrm{p}=0,001$, dengan koefisien korelasi sebesar 0,500. Penelitian lain dari mahasiswa psikologi Universitas Negeri Surabaya angkatan 2017 yang dilakukan oleh Rosyadi (2018). Dari hasil penelitian, dapat diketahui bahwa grit memiliki hubungan positif bertaraf sedang dengan subjective well-being. Hal ini dapat dilihat dari uji korelasi Spearman's rho yang mengungkap nilai signifikansi kurang dari 0,05 ( $\mathrm{p}=0,000)$, dengan koefisien korelasi sebesar 0,500.

Jika penelitian-penelitian tersebut mengatakan jika grit memiliki hubungan dengan subjective well-being, maka pada penelitian berikut mengatakan bahwa ada variabel lain yang mempengaruhi subjective well-being. Penelitian oleh Lan (2019) mengatakan bahwa subjective wellbeing pada siswa di Cina berkaitan dengan nilai akademik. Semakin tinggi nilai akademik, maka semakin tinggi pula subjective well-being, begitu juga sebaliknya. Hal ini dikarenakan budaya mereka lebih kepada memprioritaskan pendidikan. Penelitian kedua oleh Prasetyo (2018) juga menunjukkan bahwa persepsi terhadap iklim sekolah memiliki hubungan dengan subjective wellbeing. Persepsi yang dimiliki siswa terhadap iklim sekolah mampu membentuk subjective wellbeing pada siswa. Selanjutnya penelitian yang dilakukan Kusuma (2019) menyebutkan bahwa peer suport atau dukungan teman sebaya dapat memberikan pengaruh pada subjective well-being siswa.

Berdasarkan penjelasan pada latar belakang di atas dapat diketahui bahwa siswa pesantren Darul Hikmah Tulungagung memiliki subjective well-being yang tinggi dan salah satu pengaruhnya adalah grit. Hal ini terlihat dari aktivitas mereka selama di pesantren. Meski berbagai kegiatan dan permasalahan yang tejadi, tetap membuat para siswa bertahan untuk tetap tinggal di pesantren. Meski demikian, terdapat beberapa faktor lain yang dapat meningkatkan subjective well-being mereka. Hal ini menarik untuk diteliti karena subjective well-being mereka yang cukup baik selama mengikuti proses pendidikan di pesantren. Selain itu juga untuk mengetahui hubungan antara grit dengan subjective well-being pada siswa MA di pesantren.

\section{Metode Penelitian}

Penelitian ini menggunakan metode kuantitatif dengan pendekatan korelasional. Penelitian ini dilakukan di Pondok Pesantren Darul Hikmah Tulungagung dengan populasi siswa MA baik putra maupun putri yang berjumlah 372 siswa. Sampel pada penelitian ini yaitu siswa kelas X MA yang dulu juga sekolah di MTs pesantren tersebut. Skala yang digunakan untuk mengukur subjective well-being bernama The Modified BBC Subjective Well-Being (BBC-SWB) dari Pontin, Schwannauer, dan Kinderman (2013). Sedangkan skala grit menggunakan grit scale dari Duckworth dan Quinn (2009). Kedua alat ukur tersebut dimodifikasi menyesuaikan subjek yang diteliti. Dari skala tersebut, diperoleh nilai 15 aitem valid dengan tingkat reliabilitas 0,814 untuk subjective well-being dan 10 aitem valid dengan tingkat reliabilitas 0,626 untuk grit. Pengolahan data pada penelitian ini menggunakan korelasi product moment dari Karl Pearson karena data yang digunakan merupakan data parametrik dan dengan bantuan program SPSS Statistics 20 .

\section{Hasil Penelitian}

Deskripsi statistik data subjective well-being dan grit pada siswa MA di pesantren adalah sebagai berikut

Tabel 1 Kategorisasi Subjective Well-being

\begin{tabular}{ccccc}
\hline Kategorisasi & Rumus Norma & Nilai Norma & F & Persentase \\
\hline Tinggi & $\mathrm{M}+1 \mathrm{SD} \leq \mathrm{X}$ & $40 \leq \mathrm{X}$ & 108 & $95,6 \%$ \\
Sedang & $\mathrm{M}-1 \mathrm{SD} \leq \mathrm{X} \leq \mathrm{M}+1 \mathrm{SD}$ & $25 \leq \mathrm{X} \leq 40$ & 5 & $4,4 \%$ \\
Rendah & $\mathrm{X}<\mathrm{M}-1 \mathrm{SD}$ & $\mathrm{X}<25$ & - & - \\
\hline
\end{tabular}

Dari tabel tersebut dapat diketahui bahwa 95,6\% atau 108 siswa memiliki subjective wellbeing tinggi dan $4,4 \%$ atau 5 siswa memiliki subjective well-being sedang. Sedangkan tidak ada siswa yang berada di kategori subjective well-being rendah. Tabel tersebut menunjukkan jika mayoritas siswa memiliki subjective well-being yang tinggi. 
Tabel 2 Kategorisasi Grit

\begin{tabular}{ccccc}
\hline Kategorisasi & Rumus Norma & Nilai Norma & F & Persentase \\
\hline Tinggi & $\mathrm{M}+1 \mathrm{SD} \leq \mathrm{X}$ & $30 \leq \mathrm{X}$ & 18 & $15,9 \%$ \\
Sedang & $\mathrm{M}-1 \mathrm{SD} \leq \mathrm{X} \leq \mathrm{M}+1 \mathrm{SD}$ & $20 \leq \mathrm{X} \leq 30$ & 91 & $80,6 \%$ \\
Rendah & $\mathrm{X}<\mathrm{M}-1 \mathrm{SD}$ & $\mathrm{X}<20$ & 4 & $3,5 \%$ \\
\hline
\end{tabular}

Dari tabel tersebut dapat diketahui bahwa $15,9 \%$ atau 18 siswa memiliki grit yang tergolong tinggi, 80,6\% atau 91 siswa pada kategori sedang, dan 3,5\% atau 4 siswa pada kategori rendah. Sehingga dapat dikatakan bahwa sebagian besar siswa memiliki tingkat grit dalam rentang yang sedang.

Dari tabel di atas terlihat bahwa minimal grit yaitu 13,00, nilai maksimal 33,00, nilai ratarata 25,67 , dan nilai setandar deviasinya 3,384 . Sedangkan nilai minimal subjective well-being yaitu 37,00 , nilai maksimal 59,00, nilai rata-rata 48,74, dan nilai setandar deviasinya 4,754 .

Tabel 4 Hasil Uji Normalitas

\begin{tabular}{llr} 
& & Unstandardized Residual \\
\hline Subjek Penelitian & & 113 \\
Parameter Normal & Rata-Rata & $0 \mathrm{E}-7$ \\
& Setandar Deviasi & 4,43578736 \\
Perbedaan Paling Ekstrim & Absolut &, 089 \\
& Positif &, 047 \\
& Negatif & -089 \\
Kolmogorov-Smirnov $Z$ & &, 947 \\
Asymp. Sig. (2-tailed) & &, 331 \\
\hline
\end{tabular}

Terlihat dari tabel tersebut bahwa nilai signifikansinya 0,331 . Sehingga data yang digunakan berdistribusi normal karena 0,331 >0,05.

Tabel 5 Hasil Uji Linieritas

\begin{tabular}{|c|c|c|c|c|}
\hline & & 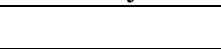 & F & Sig. \\
\hline Subjective Well- & & Kombinasi & 1,600 & ,088 \\
\hline Being & & Linearitas & 15,668 &, 000 \\
\hline$><$ & Antar Kelompok & Deviasi dari &, 595 & ,863 \\
\hline
\end{tabular}

Terlihat dari tabel di atas bahwa nilai deviasi dari linieritas yaitu 0,863 $>0,05$. Maka dua variabel subjective well-being dan grit memiliki hubungan yang linier.

Tabel 6 Hasil Uji Product Moment

\begin{tabular}{llcc}
\hline & & Grit & Subjective Well-Being \\
\hline Grit & Pearson & 1 &, $360^{* *}$ \\
& Correlation & &, 000 \\
& Sig. (2-tailed) & & 113 \\
& $N$ & 113 & 1 \\
& Pearson &, $360^{* *}$ & \\
Subjective Well-Being & Correlation & & \\
& Sig. (2-tailed) &, 000 & 113 \\
& $N$ & 113 & \\
& & &
\end{tabular}


Terlihat dari tabel di atas bahwa nilai signifikansinya yaitu $0,00<0,05$. Sehingga dapat diketahui bahwa terdapat hubungan antara grit dengan subjective well-being pada siswa kelas $\mathrm{X}$ MA di Pondok Pesantren Darul Hikmah yang berjumlah 113 orang. Dapat dinyatakan bahwa hipotesis pada penelitian ini yaitu terdapat hubungan antara grit dengan subjective well-being pada siswa MA di Pesantren. Selain itu, pada nilai korelasi pearson yaitu 0,36 terlihat bahwa hubungan antara dua variabel bersifat positif, yang berarti semakin tinggi grit, maka semakin tinggi pula subjective well-being. Terakhir, pada nilai korelasi pearson juga terlihat bahwa tingkat korelasi bersifat rendah karena nilainya di antara 0,21-0,40.

\section{Pembahasan}

Hipotesis dari penelitian ini yaitu terdapat hubungan antara grit dengan subjective wellbeing pada siswa MA di pesantren. Hipotesis ini diterima karena terbukti bahwa pada penelitian yang telah dilakukan mengatakan jika grit dan subjective well-being memiliki hubungan. Terlihat dari hasil uji korelasi dengan product moment, di mana nilai siginifikansinya $0,00<0,05$ yang berarti terdapat hubungan antara grit dengan subjective well-being. Hal ini sesuai penelitian yang dilakukan oleh Vainio (2015) pada mahasiswa dan non mahasiswa. Dalam penelitiannya menyebutkan bahwa dari nilai uji korelasi diperoleh hasil nilai signifikansi $p=0,001$, dengan koefisien korelasi sebesar 0,500. Sehingga kedua variabel tersebut memiliki hubungan. Siswa dengan grit yang baik, mereka akan berusaha bertahan agar apa yang diharapkan tercapai. Sehingga muncullah sikap subjectif well-being pada diri mereka. Sebab mereka bisa menyesuaikan dirinya dengan keadaan saat di pesantren. Begitu juga pada siswa MA di Pondok Pesantren Darul Hikmah. Dari hasil observasi, mereka memiliki keteguhan agar bisa bertahan di pesantren. Para siswa berusaha menyesuaikan dirinya dengan keadaan pesantren, sehingga subjective well-being mereka tinggi.

Dari kategori tingkat subjective well-being dan grit pada subjek yang diteliti, disebutkan bahwa $95,6 \%$ atau 108 siswa memiliki subjective well-being tinggi dan $4,4 \%$ atau 5 siswa memiliki subjective well-being sedang. Sedangkan tidak ada siswa yang berada di kategori subjective wellbeing rendah. pada variabel grit menyebutkan bahwa $15,9 \%$ atau 18 siswa memiliki grit yang tergolong tinggi, 80,6\% atau 91 siswa pada kategori sedang, dan 3,5\% atau 4 siswa pada kategori rendah. Sehingga dapat disimpulkan bahwa siswa MA di Pondok Pesantren Darul Hikmah didominasi dengan tingkat subjective well-being yang tinggi dan tingkat grit yang sedang.

Menurut Pontin, Schwannauer, dan Kinderman dalam Faridl (2018) subjective well-being merupakan penilaian individu tentang dirinya mengenai gambaran kesejahteraan yang mencangkup lingkungan di sekitar individu, respon perilaku yang dilakukan dan juga konsekuensi subjektif dari saling keterkaitan antara proses tersebut. Dari pengertian ini maka dapat diketahui bahwa siswa MA kelas X di Pondok Pesantren Darul Hikmah dominan mampu berpikir positif tentang diri mereka. Mereka juga merasa nyaman dengan keadaan lingkungan pesantren. Sedangkan untuk grit, sikap tersebut berada di taraf sedang. Namun juga merupakan salah satu yang mempengaruhi terbentuknya subjective well-being. penjelasan tentang grit menurut Duckworth (2007) yaitu kecenderungan untuk mempertahankan ketekunan dan semangat atau keinginan yang besar dalam mengejar tujuan jangka panjang. Dari sini dapat diketahui bahwa para siswa dalam mempertahankan ketekunan dan keinginan mereka untuk waktu yang lama cenderung sedang. Tidak begitu kuat, namun juga tidak lemah.

Pada uji product moment, disebutkan bahwa kedua variabel tersebut memiliki hubungan positif. Hal ini terlihat dari nilai pearson correlation yaitu 0,360. Artinya, semakin tinggi grit pada siswa, maka semakin tinggi pula subjective well-being mereka. Begitu juga sebaliknya, semakin rendah grit maka semakin rendah pula subjective well-being mereka. Meski demikian, tingkat korelasinya tidak cukup tinggi yaitu sebesar 0,360 , nilai tersebut terdapat pada rentang nilai 0,21 0,40 . Sehingga dapat diketahui bahwa ada variabel lain yang lebih berpengaruh, namun tidak diteliti pada penelitian ini. Penelitian yang dilakukan Prasetyo (2018) menunjukkan bahwa persepsi terhadap iklim sekolah berhubungan dengan subjective well-being. Sedangkan penelitian yang dilakukan oleh Kusuma (2019) mengatakan bahwa peer suport dapat meningkatkan subjective wellbeing pada siswa. Penelitian lain yang dilakukan Lan (2019) menyebutkan bahwa subjective wellbeing pada siswa di Cina terjadi jika nilai akademik mereka baik. Dari tiga penelitian tersebut 
dapat diketahui bahwa variabel lain yang memiliki hubungan dengan subjective well-being adalah persepsi terhadap iklim sekolah, peer suport, dan nilai akademik.

\section{Kesimpulan}

Sesuai hasil penelitian yang didapatkan, maka dapat disimpulkan bahawa Setelah terdapat hubungan antara grit dengan subjective well-being pada siswa MA di pesantren. Selain itu juga diketahui bahwa semakin tinggi grit pada siswa, maka semakin tinggi pula subjective well-being mereka. Dari penelitian ini, peneliti memberikan saran pada siswa agar berusaha memiliki grit yang baik atau sikap lain subjective well-being mereka tetap bertahan pada tingkat tinggi. dengan demikian para siswa bisa bertahan dan mampu menyelesaikan pendidikannya di pesantren. Sedangkan untuk pengajar untuk terus memperhatikan keadaan baik dari segi lingkungan maupun individual siswa. Hal ini bertujuan agar subjective well-being mereka tetap bertahan dengan baik Pengaruh-pengaruh positif lain juga bisa diberikan agar subjective well-being bisa semakin meningkat. Selanjutnya untuk peneliti berikutnya agar bisa menggunakan kategori sampel lain, bukan hanya satu kelas saja sehingga lebih variatif dan bisa terukur keseluruhan siswa. Selain itu, juga bisa menggunakan variabel bebas lain yang lebih berpengaruh dalam meningkatkan subjective well-being pada siswa.

\section{Daftar Pustaka}

Akbag, M. (2017). Predictive Role of Grit and Basic Psychological Needs Satisfaction on Subjective Well-Being for Young Adults. Journal of Education and Practice.

Azwar, S. (2008). Reliabilitas dan Validitas. Yogyakarta: Pustaka Pelajar.

Berlita, D. A. (2014). Hubungan Antara Sikap Syukur dengan Ksejahteraan Subjektif Siswa MAN Yogyakarta 1. Skripsi.

Diener, E. (2003). Personality, Culture, and Subjective Well-Being: Emotional and Cognitive Evaluation of Live.

Disabato, D. J. (2019). Is Grit Relevant to Well-Being and Strengths? Evidence Across the Globe for Separating Perseverance of Effort and Consistency of Interests. Journal of Personality, 194211.

Duckworth, A. L. (2007). Grit: The Power of Passion and Perseverence. New York: Library of Congress Cataloging in Publication Data.

Duckworth, A. L. (2009). Development and Validation of the Short Grit Scale. Journal of Personality Assessment, 166-174.

Faridl, M. M. (2018). Pengaruh Orientasi Religius, Dukungan Sosial dan Sel-Compassion Terhadap Subjective Well-Being Santri. Skripsi.

Feldman, R. S. (2012). Pengantar Psikologi. Jakarta: Salemba Humanika.

Hossaini. (2017). Predicting General Well-Being Based on Resiliency Protective Factors and Demographics in Adolescents: The Mediating Role of Emotional Stability. International Journal of School Health.

Jin, K. (2017). Grit, Basic Needs Satisfaction, and Subjective Well-Being. Journal of Individual Differences, 29-35.

Johana, E. (2011). Psikologi Klinis Pengantar Terapan Mikro \& Makro. Jakarta: Erlangga.

Konu, A. (2002). Factor Structure of The School Well-Being Model. Health Education Research, 732742 .

Kusuma, P. A. (2019). Peningkatan Subjective Well-being in School Pada Siswa Melalui Peer Support And Teaching Method Program. Jurnal Psikologi Sains dan Profesi, 31-42.

Lampropoulou, A. (2018). Personality, School, and Family: What is Their Role in Adolescents Subjective Well-Being. Journal of Adolescence, 12-21.

Lan, X. (2019). Direct and Interactive Effects of Perceived Teacher-Student Relationship and Grit on Student Well-Being Among Stay-Behind Early Adolescents in Urban China. Learning and Individual Differences, 129-137.

Mahmud. (2010). Psikologi Pendidikan. Bandung: CV Pustaka Setia.

Moen, F. (2020). Grit: A Unique Protective Factor of Coaches Well-Being and Burnout?

Muhid, A. (2012). Analisis Statistik. Sidoarjo: Zifatama. 
Pontin, E. (2013). A UK Validation of A General Measure of Subjective Well-Being: The Modified BBC Subjective Well-Being Scale (BBC-SWB). Helath and Quality of Life Outcomes.

Prasetyo, R. A. (2018). Persepsi Iklim Sekolah dan Kesejahteraan Subjektif Siswa di Sekolah. Jurnal Psikologi Teori dan Terapan, 133-144.

Rosyadi, A. K. (2018). Hubungan Antara Grit dengan Subjective Well-Being Pada Mahasiswa Psikologi Universitas Negeri Surabaya Angkatan 2017. Jurnal Psikologi.

Salles, A. (2013). The Relationship Between Grit and Resident Well-Being. The American Journal of Sugery.

Santoso, S. (2002). SPSS versi 11.5 Cetakan Kedua. Jakarta: Gramedia.

Seligman, M. E. (2011). Flourish: A Visionary New Understanding of Happiness an Well-Being. New York: Free Press.

Sudarji, S. (2020). Perbedaan Grit Pada Mahasiswa Perantau dan Bukan Perantau di Universitas "X" . Jurnal Psikologi .

Sugiyono. (2010). Metode Penelitian Kuantitatif Kualitatif dan R\&D. Bandung: Alfabeta.

Tiittanen, M. (2014). Grit and Different Aspects of Well-being: Direct and Indirect Effects via Sense of Coherence and Authenticity. Thesis.

Vainio, M. M. (2015). Grit and Different Aspects of Well-Being: Direct and Indirect Relationships via Sense of Coherence and Authenticity.

Vivekananda, N. L. (2017). Studi Deskriptif mengenai Grit pada Mahasiswa Fakultas Psikologi Universitas Kristen Maranatha Bandung. Jurnal Psikologi.

Weisskirch, R. S. (2019). Grit Applied Within: Identity and Well-being. An International Journal of Theory and Research, 98-108.

Wijayanti, P. A. (2018). Peer Relation Sebagai Prediktor Utama School Well-Being Siswa Sekolah Dasar. Jurnal Psikologi.

Zeng, G. (2016). Effect of Growth Mindset on School Engagement and Psychological Well-Being of Chinese Primary and Middleschool Students: The Mediating Role of Resilience. Frontiers in Psychology.

Zulkifli, H. R. (2018). Pengaruh Grit, Syukur, School Angegement Terhadap Kesejahteraan Subjektif Mahasiswa Perantau. Skripsi. 